\title{
Maya Settlement Patterns at El Pilar: Inventory of the Cultural Resources of the El Pilar Archaeological Reserve for Maya Flora and Fauna: Lidar and New Protocols for Archaeology under the Canopy
}

\author{
Anabel Ford* \\ American archaeologist, University of California, USA \\ Submission: January 25, 2018; Published: March 29, 2018 \\ *Corresponding author: Anabel Ford, American archaeologist, University of California, USA, Email: anabel.ford@ucsb.edu
}

\section{Opinion}

Population growth, land use, and agricultural needs figure among the prominent issues facing the world today. At a global scale, population growth fuels land-use changes that can lead to deforestation, erosion, and land degradation. All the while, forests globally, especially in the tropics, are under threat from human impact, climate change, deforestation, and unsustainable land use. Understanding past land use can contribute to our understanding of conditions of the tropics and archaeology has much to contribute. This is the guiding perspective of work at El Pilar.

We know that settlements leave enduring tracks of human land use for archaeologists to identify, map, and interpret. Investigating patterns of settlements on the landscape has been the cornerstone of archaeological investigations of subsistence and of political organization of the past. For the Maya, land use intensity can be evaluated by residential unit dispersal and settlement density and wealth distribution can be assessed by residential unit and settlement size and composition. This is where archaeology can play a significant role in understanding differentiation on the landscape. The evidence of residential patterns and public architectural investment are the archaeological evidence of systematic priorities and in the case of preindustrial agrarian societies as the Maya, this evidence reflects the balance and tensions between the general subsistence needs and specific political economic goals. These are the long-term goals of our research at El Pilar.

We have been involved in a full survey of El Pilar with the ultimate aim to develop a complete map of the entire $20 \mathrm{sq}$. km of the El Pilar Archaeological Reserve for Maya Flora and Fauna. This will contribute to the growing inventory of the cultural resources of El Pilar and other areas of the Maya forest as a basis for understanding ancient Maya land use of the past, for cultural resource management for the present, and for alternative models of sustainability in the future. We have been gathering archaeological survey data at the El Pilar Archaeological Reserve for Maya Flora and Fauna using LiDAR as the foundation of discovery. We have begun to incorporate these data for El Pilar in out Maya Forest Atlas for analyses and interpretation of site level land that can be compared with local and regional scale data (http://marc-ucsb.opendata.arcgis.com/).

It was 3,000 years ago that archaeologists have identified the initial emergence of the agrarian Maya civilization. The evidence of growth and development endured for millennia based on the success. The settlements suggest a pattern of dispersed farmers infilling the preferred areas and intensifying their use over time, supporting the political economy of elite at major public centers. Assessment of populations and their distribution rely on understanding settlement patterns, and great strides have been made at a broad scale. To understand the relationship between the subsistence potentials and the political demands that bear on interpretations of land management, detailed site-specific surveys as the one we are developing at El Pilar are required. These surveys need to incorporate accurate topographic, soil, and settlement data, data largely illusive until now. With new LiDAR data processed with the GIS (Geographic Information System), we are in a position to test a new field protocol and collect the detail needed to understand influences of growth and development of agricultural pursuits and land use.

Acquiring the information on settlement patterns not always straightforward in the case of forests such as found in the Maya area. Just locating the sites presents a challenge. Over the decades, strategies have relied on pedestrian surveys and location of sites with transits and pace and compass. These have 
provided important windows into the landscape of the Maya, but are restricted because of the nature of sampling. Today's new investments in LiDAR is transforming this challenge. We now have the ability to gather digital data on topography and identify elements and features under the canopy. Yet the small features, those attributable to house structures that make of the residential component - likely the farming majority of the Maya - are still illusive. With LiDAR, the topography is revealed and the large buildings and plazas are clear, it is the building blocks of the society, the residential unit as the minimum component of the settlement and the basic unit of all land use patterns that is fundamental to the ancient economy and essential to record. These smallest units are the focus of the El Pilar settlement survey program, an outgrowth of the long-term goals set up with the Belize River Archaeological Settlement Survey (BRASS) in 1983. The surveys will continue on the path toward the aim of identification of the cultural resources of El Pilar.

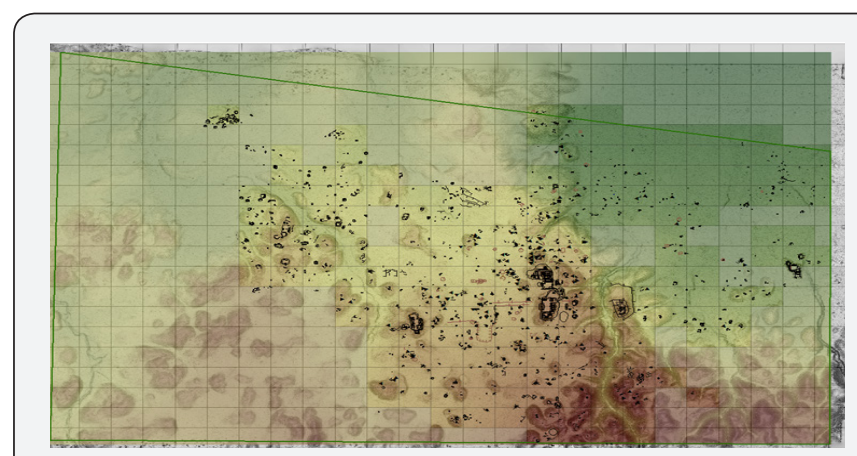

Figure 1: Completed Surveyed Areas (clear) and Major Architectures Features based on LiDAR.

Over the past three years we have developed a survey protocol initiated with the LiDAR. With the identification of features on the LiDAR we have been able to implement to protocol in the field. In this way, we have discovered the value of LiDAR for archaeology and that is you still need the archaeologist to validate the elements and features in the field. Initially, we surveyed the landscape immediately around the main monuments of El Pilar before and after LiDAR, and have been able to demonstrate that the traditional surveys with transects and pace and compass mapping serve well. In fact, the margin of locational error in our original surveys are comparable to the error factor to the standard GPS units commonly used in the field, that is c. $7 \mathrm{~m}$ radius of the actual targeted datum point. After reconfirming our original surveys, we selected example areas to survey: 1) areas without many visible LiDAR elements and areas with significant visible LiDAR elements on the digital surface map. We discovered that the LiDAR was largely faithful to the complexity of the traversed landscape and our mapping discoveries. Our trials at the survey, our refinement of our field survey protocol, and our current coverage at $50 \%$ of the whole reserve area encourage our completion effort in the production of an inventory of cultural remains at El Pilar (Figure 1).

There has been a long tradition of survey methods and techniques in the Maya area relying on the establishment of transects with survey engineering instruments. Originating from public centers, coverage was by archaeologist traversing the terrain on foot. From known centers, archaeologists expanded into the unknown to assess topography, identify cultural features, and map settlement locations and configurations. With these traverses, Maya archaeologists have determined that settlements are dispersed in the well-drained uplands. These studies provide vital information on settlement densities with a focus on the uplands, yet lack the detailed scale to analyze the relationship of residential forms and configuration with respect to the nuanced geographic and inferred political influences. These basic strategies are the nuts and bolts of survey and a technique we still rely on. The LiDAR elements are our guide, but the visible validation and actual maps that can only be done in the field and under the canopy. This process of validation takes a minimum of two teams of archaeologists and forest gardeners one full month to complete $1 \mathrm{sqkm}$.

Table 1: Dominant Plants of the Maya Forest recorded in the El Pilar Survey.

\begin{tabular}{|c|c|c|}
\hline Scientific Name & Common Name & Pollinator \\
\hline Spondiasradlkoferi & hogplum & insects \\
\hline Aspidospermacruentum & malerio & insects \\
\hline Attalea cohune* & corozo & insects \\
\hline Cryosophilastauracantha & give-and-take & beetles \\
\hline Sabal morrisian* & bay leaf palm & insects \\
\hline Tabebuiarosea & mayflower & bees \\
\hline Burserasimarouba* & gumbo limbo & bees \\
\hline Licania platypus & succotz & moths \\
\hline Lonchocarpuscastilloi & manchich & insects \\
\hline Piscidiapiscipula & jabin & bees \\
\hline Zuelaniaguidonia & tamay & bees \\
\hline Swieteniamacrophylla & mahogany & insects \\
\hline Brosimumalicastrum* & ramon & wind \\
\hline Alseisyucatanensis & wild mamey & moths \\
\hline Simirasalvadorensis* & john crow redwood & moths \\
\hline Talisiaoliviformis* & kinep & bees \\
\hline Pouteriareticulata & zapote negro & insects \\
\hline Pouteriacampechiana & zapotillo & insects \\
\hline Manilkarazapota* & chicle & bats \\
\hline Vitexgaumeri & fiddlewood & bats \\
\hline
\end{tabular}

As we compile the data we have collected, we have created spatial layers of the descriptive data that include: mounds, plazas, chultun, terraces, quarries, aguadas and depressions, berms, looter trenches, and historic features. At the same time, we map the cultural features, we itemize the presence of the dominant plants of the Maya forest (Table 1) and we record observations of other trees known to the Master Forest Gardeners and validated by professional botanists. Novel in our survey is the inclusion of the trees that have potential for important forest resources needed by neighboring communities including fruits, seeds, 
and medicinal products. Once the architecture is mapped and incorporated in the GIS, we record the additional non-spatial data on the size and composition of residential units. When we conclude our survey, we will have a robust data base suitable for cultural and natural resource management of the reserve (Figure 2).

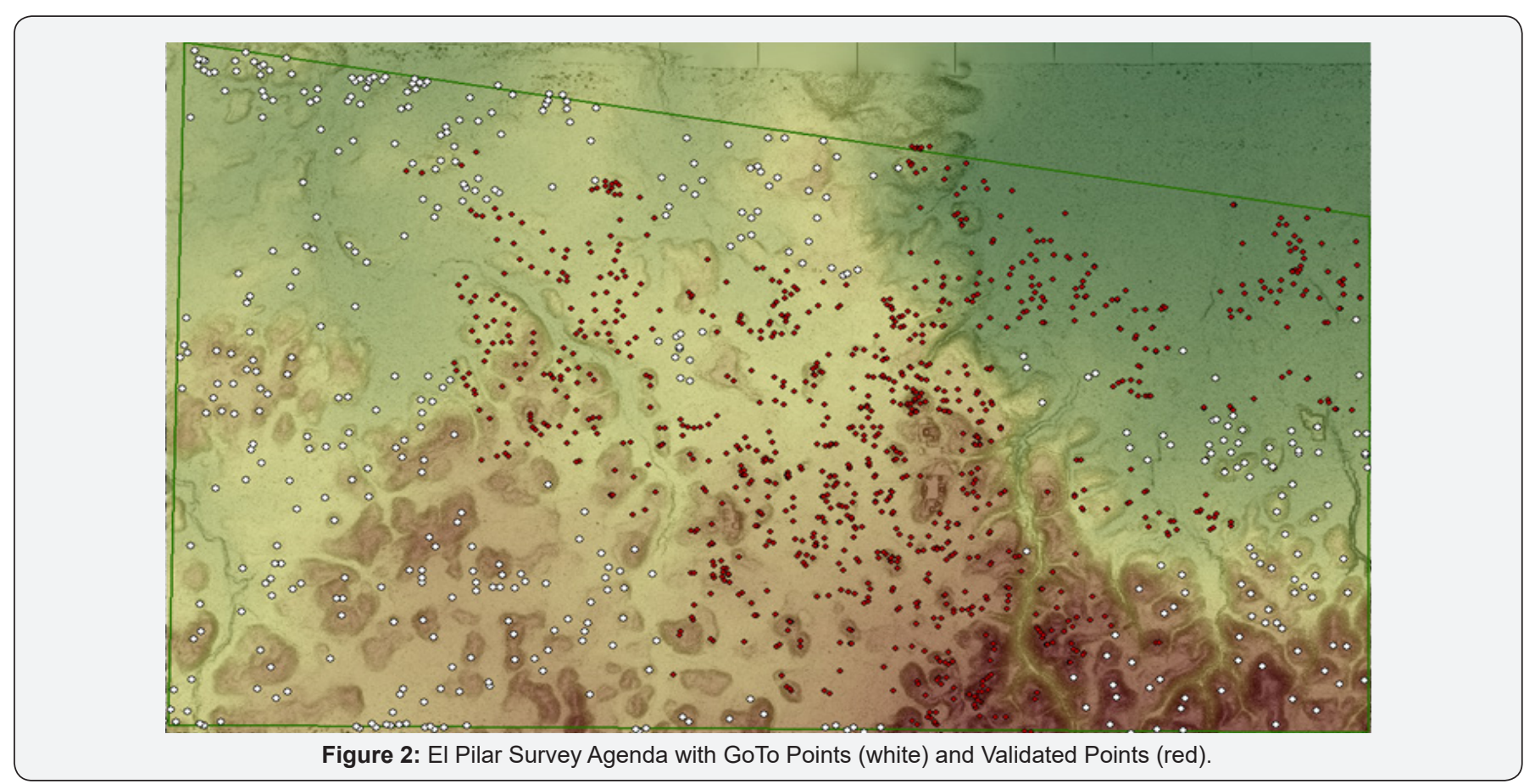

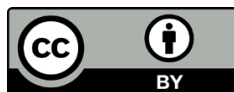

This work is licensed under Creative Commons Attribution 4.0 License DOI: 10.19080/GJAA.2018.03.555610

\section{Your next submission with Juniper Publishers} will reach you the below assets

- Quality Editorial service

- Swift Peer Review

- Reprints availability

- E-prints Service

- Manuscript Podcast for convenient understanding

- Global attainment for your research

- Manuscript accessibility in different formats ( Pdf, E-pub, Full Text, Audio)

- Unceasing customer service

Track the below URL for one-step submission https://juniperpublishers.com/online-submission.php 